\title{
Attitudes of Croatian Consumers About Mobile Messenger Chatbots
}

Damir Dobrinić

Faculty of Organization and Informatics

University of Zagreb, Varaždin. Croatia

Iva Gregurec

Faculty of Organization and Informatics

University of Zagreb, Varaždin. Croatia

\section{Dunja Dobrinić}

Faculty of Organization and Informatics

University of Zagreb, Varaždin. Croatia damir.dobrinic@foi.unizg.hr

iva.gregurec@foi.unizg.hr

du.dobrinic@foi.unizg.hr

\begin{abstract}
This paper aims to investigate Croatian consumers' attitudes about mobile messenger chatbots (MMC) and their propensity to use them. The proposed conceptual model is based on the Technology Acceptance Model (TAM) and Innovation Diffusion Theory (IDT). The research was conducted through an anonymous survey questionnaire available on the social network Facebook. The empirical research results show that perceived usefulness, perceived ease of use, compatibility, and attitude towards mobile advertisements are statistically significantly related to attitude towards mobile messenger chatbots. No negative correlation was found between internet privacy concern and consumer attitudes about mobile messenger chatbots. A positive correlation was found between attitude towards using mobile messenger chatbots and behavioral intention. In addition to the scientific contribution in better predicting chatbots' acceptance as a communication and promotional tool, the research results will also help marketing experts design advertising campaigns via mobile messenger chatbots.
\end{abstract}

Keywords: TAM model, IDT, mobile messenger chatbots, attitude toward $\mathrm{MMC}$

\section{Introduction}

Today we are in a time of intensive digitalization in which new technologies (artificial intelligence, virtual and augmented reality, Big data, blockchain, Internet of things, cloud computing, robotics, process automation ...) that permeate all aspects of human 
life have been developed and available. In this regard, companies are initiating the process of the digital transformation of their business. The application of new technologies to marketing enables the development of personalized communication with customers leading to higher marketing productivity and customer satisfaction [1]. Krum [2] points out that mobile marketing, as part of digital marketing, represents the marketing of the future precisely because it allows customers to find the product and all the information about it when they need it. Marr [3] also calls the fourth technological revolution the "smart revolution" whose heart is Big data. A significant portion of data or digital traces people leave using their mobile devices. As Krum [2] states, mobile devices represent the most personal technological thing a person has or will have. The mobile device cares about us, it does not borrow, it remembers all our activities and movements, it contains important data, addresses ..., it provides us with the entertainment we want, etc. As such, it is an ideal medium for targeted direct communication and creating relationships with customers. Tong et al. [4] talk about high hyper-context personalized targeting where based on available data (location, time, environment, etc.) relevant content is delivered to the recipient.

Mobile messenger chatbots are emerging as a newer method for communicating with customers, based on the application of artificial intelligence. Chaffey \& Chadwick [5] state that "chatbots mimic human intelligence by being able to interpret consumer's queries and complete orders for them". The term occurs in different variants so that the names are found in the literature: chatterbots, virtual assistants, virtual agents, intelligent agents, or web-bots [6]. Such interaction with users can take place in text or voice form and are created for various reasons, whether it is entertainment, providing information, developing dialogue, website guide, frequently asked questions (FAQ), virtual support agent, virtual sales agent, survey taker, quiz host, learning tutor, and chat-room [7]. The American Marketing Association states that chatbots are the future of marketing, according to research which claims that almost $90 \%$ of innovation-oriented marketing professionals consider innovation and real-time customer engagement as top priorities. In comparison, $67 \%$ of millennials said they like to buy brands that use chatbots [8] [9]. A review of existing research has found that mobile messenger chatbots (MMC) as a new form of communication with customers is still not sufficiently analysed in terms of their acceptability.

This paper aims to investigate Croatian consumers' attitudes about MMC and their propensity to use them. The motivation for the implementation of this research is the lack of similar research, primarily because it is a technology that is just beginning to be used significantly. The empirical research was conducted on a sample of 214 persons who correctly filled out the survey questionnaire. Structural Equation Modeling (SEM) using IBM SAS and AMOS statistical tools was used to test research propositions.

Artificial intelligence is not the future; it is already used and makes life easier. $\mathrm{MMC}$ is a relatively new marketing tool that will certainly become an essential part of future marketing strategies. The contribution of this paper is to provide knowledge about its acceptance by users that is currently lacking. Knowledge of attitudes regarding the application of MMC as a form of using artificial intelligence in communication with consumers will also contribute to understanding consumer's 
behaviour related to the widespread use of artificial intelligence in interaction with consumers.

The paper consists of 5 units. After the introductory part, an overview of previous research is given, and a research propositions was proposed in the second part. The third part presents the research methodology and results, while discussion and implications are in the fourth part of the paper. The conclusion is formulated in the last fifth part of the paper.

\section{Theory and research model development}

According to Statista [10] projections, by 2022, there will be 3 billion users of mobile messenger applications worldwide. The reasons for the great popularity of these applications, especially among the younger population, lie in the fact that "they are free, globally available and very easy to use" [14] as well as to serve for "real-time message transmission" [15]. The most popular global mobile messaging apps 2020 are WhatsApp, Facebook Messenger, WeChat, QQ, Telegram, and Snapchat [11]. Due to high prevalence, a large number of users, and fast exchange of information between users, companies turn to communication via popular mobile messenger applications. This popularity and the development of artificial intelligence lead to creating a new form of commercial communication with customers that excludes human customer support. Using messenger chatbot, customers communicate directly with the machine [17] [18]. The use of mobile messenger chatbots (MMC) in promotional/sales communication has just begun, and research that would deal with their acceptance as a form of communication is still lacking [8]. A review of the research studies found that only a few papers explored the attitude towards chatbot technology applied in mobile commerce.

Based on the literature analysis, a conceptual research framework was formed, and research propositions were proposed. (Figure 1)

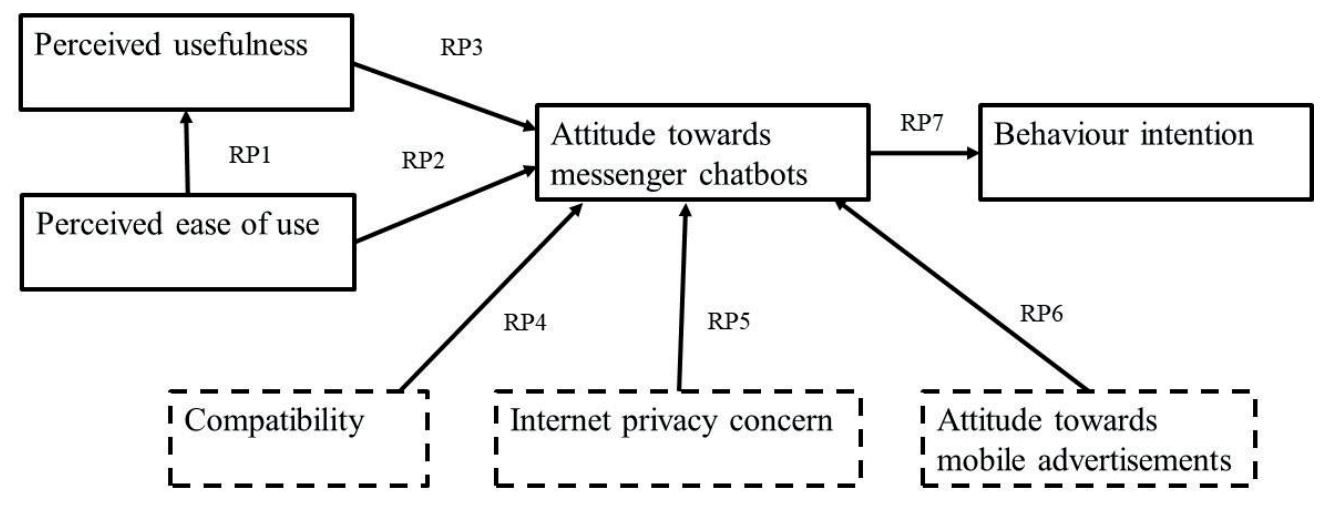

Figure 1. Conceptual model 
The proposed conceptual model is based on the Technology Acceptance Model TAM and Innovation Diffusion Theory DIT. The Technology Acceptance Model is used to determine the intent to use technology by exploring users' attitudes about that technology. The presumption is that the technology will be accepted and used if the attitude about it is more positive. It is the research of attitude that makes this model interesting because it points to the fact that users decide to use an innovation based on making their rational decisions [8]. The model assumes that users' attitudes about technology are influenced by perceived usefulness and perceived ease of use of that technology. A very similar concept of determining the adoption of an innovation is the DIT model, which defines five basic innovation factors that influence the acceptance of an innovation [12]. Subsequent research reduces them to three: relation advantage, compatibility, and complexity [13]. The first two factors are similar to the perceived usefulness and perceived ease of use factors from the TAM model. Complexity is included in the TAM model as a predictor of technology stance bringing the two compatible models together. Within the conceptual model, the impact of internet privacy concern and attitude towards mobile advertising on the attitude about technology is also considered. Research papers that investigate the application of mobile technology in business pay special attention to the risk factor. Within this paper, risk refers to the potential threats to privacy. Mobile messenger chatbots (MMC) are also used in advertising, so it is useful to identify user attitudes about mobile advertising and explore their impact on attitudes about MMC as a new technology/innovation.

\subsection{Perceived ease of use (PEOU)}

Perceived ease of use as a basic prerequisite for accepting an innovation Davis [14] defines it as "the degree to which a person believes that using a particular system would be free of effort". According to Al-Hurjan et al. [15], users form a positive attitude about the tools (programs) they use if their use does not require much effort. In the absence of research related to the acceptance of MMC, some studies of the acceptance of mobile advertising and mobile commerce can be useful for this research [16] [17] [18]. The partial justification for this approach lies in the fact that mobile messenger chatbots are part of mobile commerce and mobile advertising. In this regard Mao et al. [19] found the strong impact of perceived ease of use on the acceptance of mobile devices as sales and promotional channels. While Natarajan et al. [20] found the impact of ease of use on the intention to use mobile shopping applications. In the context of MMC Kasilingam [8] especially emphasizes the impact of ease of using $\mathrm{MMC}$ on positive attitude and intention to use. Based on a review of previous research, research propositions $\mathrm{RP}_{1}$ and $\mathrm{RP}_{2}$ were proposed. The acronym MMC will be used in the continuation of the term mobile messenger chatbots.

$R P_{1}$ : Perceived ease of use MMC has a positive influence on the perceived usefulness of MMC.

$R P_{2}:$ Perceived ease of use MMC has a positive influence on attitude toward $M M C$. 


\subsection{Perceived usefulness (PU)}

According to Davis [14], perceived usefulness is "the degree to which a person believes that using a particular system would enhance his or her job performance" [15]. Accordingly, a positive attitude about one of the technologies stems from the perception of its usefulness [21]. If users perceive the technology as useful, they will have a positive attitude about it. Many different studies have proven the direct impact of perceived usefulness on the intention to use some technology or innovation. Several of them also referred to mobile technology and the adoption of various mobile applications [22] [23] [24] [25]. In the context of MMC Kasilingam [8] points out that users attitudes about them will be more positive if they facilitate communication with the company and make the purchase more flexible and pleasant. Based on that observations, the research proposition $\mathrm{RP}_{3}$ was proposed. $M M C$.

$\mathrm{RP}_{3}$ : Perceived usefulness of MMC has a positive influence on attitude toward

\subsection{Compatibility (CO)}

According to the Innovation Diffusion Theory (DIT) developed by Rogers [12], innovation represents ,an idea, practice, or object that is perceived as new by an individual or other unit of adoption" [26]. According to the same theory, compatibility is one of the essential elements influencing innovation acceptance speed. Rogers defines compatibility as ,the degree to which an innovation is perceived as being consistent with the existing values, needs, and past experiences of potential adopters" [27]. Chen et al. [28] emphasize that greater compatibility contributes to the faster acceptance of innovation. Several studies determine the direct positive impact of compatibility on attitude toward new technology adoption [29] [30] [8]. Mobile messenger chatbots can be viewed as an innovation, i.e., a novelty in the way of buying and selling communication. In this sense, compatibility as an indicator of innovation's response to "potential adopters' values" [29] is viewed as a factor influencing attitudes towards messenger chatbots. According to the determined importance of compatibility in innovation accepting research proposition, $\mathrm{RP}_{4}$ was proposed.

$R P_{4}$ : Compatibility has a positive influence on attitude toward MMC.

\subsection{Internet privacy concern (IPC)}

Data constitutes and will constitute highly sought-after goods. The high degree of digitization of all human activities allows relatively easy access to data that characterizes an individual, thus raising concerns about their misuse. Studies related to the using of wireless technologies particularly highlights the problem of increased concerns about accessing and using users personal data [31] [32]. The use of mobile devices in shopping ( $\mathrm{m}$-commerce) raises the issue of privacy to a higher level as users are „more identifiable, instantly identifiable, and always identifiable" [33]. The applications that users use on their mobile devices provide several different benefits; however, they also carry high risk [34]. Smartphones contain a range of personal data 
and, as such, are a very interesting target for privacy breaches and malicious activities [35]. Mobile messenger chatbots (MMC) are product of artificial intelligence where communication with machine replace human contact and it is to be expected that this kind of communication and data exchange with the machine will negatively affect the acceptance of MMC. Accordingly, research proposition $\mathrm{RP}_{5}$ was proposed.

$R P_{5}$ : Internet privacy concern has a negative influence on attitude toward MMC.

\subsection{Attitude towards mobile advertisements (ATMA)}

Attitude research is crucial in determining behavior [36] [37] [38]. Farris et al. [39] define the attitude as "a combination of what consumers believe and how strongly they feel about it." Evaluating something that is the subject of an attitude can range from extremely negative to extremely positive [40]. A few research papers deal with establishing attitudes regarding mobile marketing and mobile advertising [41] [42]. Artificial intelligence enters mobile marketing through chatbots used for the purpose of promotion, sales, and customer services. It is assumed that previous experiences related to mobile advertising will impact the acceptance of MMC as a new form of communication. Accordingly, research proposition $\mathrm{RP}_{6}$ was proposed.

$R P_{6}:$ Attitude towards mobile advertising has a positive influence on attitude toward MMC.

\subsection{Attitude towards mobile messenger chatbots (A)}

Consistent with the definitions of Davis et al. [20], the attitude about MMC arises from the mental state of the individual, which is manifested through beliefs and emotions towards MMC. In this regard, the attitude can be both positive and negative. According to Rogers [12], the attitude towards innovation is directly related to the prediction of its adoption and use. The TAM model has been integrated into many different studies of the acceptance of different technologies [43]. Authors [10] [44] in their research confirm the importance and influence of the attitude about MMC on predicting their use in the future. Based on the literature analysis for the needs of empirical research, the research proposition $R P_{7}$ was proposed.

$R P_{7}$ : Attitude toward mobile messenger chatbots has a positive influence on the intention to use.

\section{Research methodology}

\subsection{Research instrument}

For empirical research purposes, the measuring instrument used in the Eeuwen [26] research was provided and translated. In accordance with the conceptual framework of the research (Figure 1) and the set variables, the measuring instrument was divided into seven parts, each part containing the corresponding number of questions (Table 1). In addition to the usual variables tested within the TAM model, the influence of 
external variables/factors (compatibility, internet privacy concern, and attitude towards mobile advertising) on the attitude towards MMC was also tested. The compatibility factor is taken from the Innovation Diffusion Theory and the other two from previous research related to establishing attitudes regarding mobile and online advertising [45] [46] [47]. A 5-point Likert scale of agreement or disagreement with the proposed statements was used to measure attitudes within the set variables.

\subsection{Data}

The research was conducted through a survey questionnaire available on the social network Facebook. Two hundred and nineteen (214) correctly filled answers were collected from $148(69,2 \%)$ females and $66(30,8 \%)$ males. Analysing the age of the respondents, it was determined that 129 of them were under the age of $24(60.3 \%), 71$ were under the age of $27(33,2 \%)$, and 14 were under the age of $36(6,5 \%)$. Based on questions related to mobile devices' use, it was determined that the largest percentage of respondents $(33,6 \%)$ use a mobile device 2 to 3 hours a day ( 3 to 4 hours $-27,1 \%$ ), and $76,6 \%$ of them have done at least once in their lives online shopping via mobile devices. Also, the majority of respondents $(79,9 \%)$ are familiar with the term messenger chatbot, which is a good basis for research.

\subsection{Statistical methods}

The collected data were analysed using different statistical methods. In order to determine the correctness of the measuring instrument, its validity and reliability were tested. Determining validity looks at the extent to which an instrument measures what it was originally designed for. Construct validity of the research instrument was ensured through the application in theory of a well-known and widely used model of measuring the acceptance of innovation, while content validity is ensured by using literature-defined and research-tested questions (items).

To determine the degree of convergence of items within an individual construct, convergent validity was examined by calculating average variance extracted (AVE) and composite (construct) reliability (CR).

In order to check the uniqueness of the constructs, i.e., to determine their differences in terms of the absence of a large correlation between them, discriminant validity was tested.

The reliability of the measuring instrument was assessed using Cronbach's alpha coefficients, which indicates the items' internal consistency in the measured scale. As the Cronbach's alpha coefficient is considered a conservative measure that underestimates true reliability, it is often used and composite reliability (CR) in measuring internal reliability [37].

The suitability of the proposed research model from the aspect of its matching with empirical data was assessed using fit indices: Chi-square index, Goodness of fit (GIF), Adjusted goodness of fit (AGFI), Incremental fit index (IFI), Normed fit index (NFI), Comparative fit index (CFI) and Root Mean Square Error (RMSEA). 
Structural equation modelling was used to examine the relationships between variables and the strength of those relationships, i.e., to verify proposed research propositions.

\subsection{Validity analysis}

Before running a structural equation modelling measure, the instrument validity and reliability were tested. Convergent validity was examined by calculating average variance extracted (AVE) and composite reliability (CR). Composite reliability was calculated based on factor loadings determined through the implementation of confirmatory factor analysis. The cut off value for AVE is $>0.5$ and CR> 0.6 [48]. All obtained AVE and CR measurement results are within the cut-off values (Table 1).

\begin{tabular}{|c|c|c|c|c|c|c|c|c|}
\hline \multirow[b]{2}{*}{ Construct } & \multirow[b]{2}{*}{ Item } & \multicolumn{3}{|c|}{ Internal reliability } & \multicolumn{2}{|c|}{ Convergent validity } & \multirow[b]{2}{*}{ Mean } & \multirow[b]{2}{*}{ SD } \\
\hline & & $\begin{array}{c}\text { Cronbach's } \\
\text { alpha }\end{array}$ & $\begin{array}{l}\text { Item-total } \\
\text { correlation }\end{array}$ & $\begin{array}{l}\text { Factor } \\
\text { loading }\end{array}$ & $\begin{array}{l}\text { Composite } \\
\text { reliability } \\
\text { (CR) }\end{array}$ & AVE & & \\
\hline $\begin{array}{l}\text { Perceived } \\
\text { usefulness } \\
\text { (PU) }\end{array}$ & $\begin{array}{l}\text { PU1 } \\
\text { PU2 } \\
\text { PU3 } \\
\text { PU4 } \\
\text { PU5 }\end{array}$ & ,855 & $\begin{array}{l}, 869 \\
, 874 \\
, 855 \\
, 853 \\
, 850\end{array}$ & $\begin{array}{l}.793 \\
, 729 \\
, 699 \\
, 695 \\
, 866\end{array}$ & ,894 &, 576 & \begin{tabular}{l|}
3,939 \\
4,042 \\
3,393 \\
3,467 \\
3,575
\end{tabular} & $\begin{array}{l}0,757 \\
0,752 \\
0,772 \\
0,766 \\
0,851\end{array}$ \\
\hline $\begin{array}{l}\text { Perceived ease } \\
\text { of use } \\
\text { (PEOU) }\end{array}$ & \begin{tabular}{|l|} 
PEOU1 \\
PEOU2 \\
PEOU3 \\
\end{tabular} & 890 & $\begin{array}{l}, 788 \\
, 741 \\
, 843 \\
\end{array}$ & $\begin{array}{l}, 859 \\
, 779 \\
, 945 \\
\end{array}$ & 823 &, 746 & $\begin{array}{l}4,416 \\
4,140 \\
4,444 \\
\end{array}$ & $\begin{array}{l}0,671 \\
0,786 \\
0,660 \\
\end{array}$ \\
\hline $\begin{array}{l}\text { Compatibility } \\
\text { (CO) }\end{array}$ & $\begin{array}{l}\mathrm{CO} 1 \\
\mathrm{CO} 2 \\
\mathrm{CO} 3 \\
\end{array}$ & ,931 & $\begin{array}{l}, 795 \\
, 896 \\
, 893 \\
\end{array}$ & $\begin{array}{l}, 821 \\
, 945 \\
, 959 \\
\end{array}$ & ,790 &, 829 & $\begin{array}{l}3,528 \\
3,042 \\
3,062 \\
\end{array}$ & $\begin{array}{l}0,932 \\
1,018 \\
1,032 \\
\end{array}$ \\
\hline $\begin{array}{l}\text { Internet } \\
\text { privacy } \\
\text { concern (IPC) }\end{array}$ & $\begin{array}{l}\text { IPC1 } \\
\text { IPC2 } \\
\text { IPC3 } \\
\end{array}$ & ,944 & $\begin{array}{l}, 874 \\
, 907 \\
, 871 \\
\end{array}$ & $\begin{array}{l}, 906 \\
, 957 \\
, 902 \\
\end{array}$ &, 819 &, 850 & $\begin{array}{l}3,215 \\
3,084 \\
3,009 \\
\end{array}$ & $\begin{array}{l}1,048 \\
1,106 \\
1,096 \\
\end{array}$ \\
\hline $\begin{array}{l}\text { Attitude } \\
\text { towards } \\
\text { mobile } \\
\text { advertisements } \\
\text { (ATMA) } \\
\end{array}$ & \begin{tabular}{|l|} 
ATMA1 \\
ATMA2 \\
ATMA3 \\
ATMA4 \\
ATMA5 \\
\end{tabular} & 907 & $\begin{array}{l}, 710 \\
, 795 \\
, 808 \\
, 743 \\
, 782 \\
\end{array}$ & $\begin{array}{l}, 683 \\
, 739 \\
, 838 \\
, 835 \\
, 866 \\
\end{array}$ & ,868 & ,632 & $\begin{array}{l}3,654 \\
3,294 \\
2,850 \\
2,505 \\
3,280 \\
\end{array}$ & $\begin{array}{l}0,889 \\
1,031 \\
1,068 \\
1,006 \\
0,922 \\
\end{array}$ \\
\hline $\begin{array}{l}\text { Attitude } \\
\text { towards } \\
\text { messenger } \\
\text { chatbots (A) }\end{array}$ & $\begin{array}{l}\text { A1 } \\
\text { A2 } \\
\text { A3 } \\
\text { A4 } \\
\text { A5 } \\
\end{array}$ & ,861 & $\begin{array}{l}, 639 \\
, 730 \\
, 721 \\
, 747\end{array}$ & $\begin{array}{l}, 762 \\
, 702 \\
, 737 \\
, 830\end{array}$ &, 865 &, 576 & $\begin{array}{l}3,780 \\
3,668 \\
4,126 \\
3,682\end{array}$ & $\begin{array}{l}0,752 \\
0,843 \\
0,882 \\
0,894\end{array}$ \\
\hline $\begin{array}{l}\text { Behavioral } \\
\text { intention (BI) }\end{array}$ & $\begin{array}{l}\mathrm{BI} 1 \\
\mathrm{BI} 2 \\
\mathrm{BI} 3 \\
\end{array}$ & ,903 & $\begin{array}{l}, 867 \\
, 877 \\
, 843 \\
\end{array}$ & $\begin{array}{l}, 853 \\
, 834 \\
, 927 \\
\end{array}$ & ,820 &, 760 & $\begin{array}{l}3,463 \\
3,182 \\
3,271 \\
\end{array}$ & $\begin{array}{l}0,972 \\
1,087 \\
0,940\end{array}$ \\
\hline
\end{tabular}

Table 1. Validity and reliability of the measuring instrument

Discriminate validity was checked, and it was found that there is no large correlation between the constructs, i.e., the constructs show a satisfactory degree of uniqueness [49]. The discriminant validity of the research instrument is shown in Table 2. 
Cronbach's alpha coefficient was calculated to determine the research instrument's reliability. The results shown in Table 1 show that all obtained values are above the limit of 0.7 , which represents the lower limit of acceptability [50]. The obtained values for composite reliability also show the research instrument's high reliability, which is above the cut-off values. This confirmed the satisfactory internal consistency within each construct (variable).

\begin{tabular}{|l|r|r|r|r|r|r|r|}
\hline & \multicolumn{1}{c|}{ PU } & \multicolumn{1}{c|}{ PEOU } & \multicolumn{1}{c|}{ CO } & \multicolumn{1}{c|}{ IPC } & \multicolumn{1}{c|}{ ATMA } & \multicolumn{1}{c|}{ A } & BI \\
\hline PU & $\mathbf{7 9 5}$ & & & & & & \\
\hline PEOU &, 602 & $\mathbf{, 8 6 4}$ & & & & & \\
\hline CO &, 699 &, 475 & $\mathbf{9 0 9}$ & & & & \\
\hline IPC & 0,08 & $-0,02$ & 0,08 & $\mathbf{9 2 1}$ & & & \\
\hline ATMA &, 458 &, 283 &, 563 &, 255 & $\mathbf{, 7 9 5}$ & & \\
\hline A &, 749 &, 623 &, 664 & $-0,02$ &, 376 & $\mathbf{, 7 5 9}$ & \\
\hline BI &, 751 &, 517 &, 731 &, 164 &, 692 &, 741 & $\mathbf{8 7 2}$ \\
\hline
\end{tabular}

PU-perceived usefulness, PEOU-perceived ease of use, CO-compatibility, IPCinternet privacy concern, ATMA- consumer's attitude towards mobile advertisement, BI- behavioral intention

Table 2. Discriminant validity

\subsection{Estimation of model fit}

In order to estimate the adequacy of the research model, i.e., its coincidence with the actual data, confirmatory factor analysis was performed using the statistical tool IBM AMOS 26. Fit indices were used to present the model fit in terms of matching empirical data with the theoretical model. Fit indices with corresponding values and cut-off values are shown in Table 3 . Based on the obtained values, a good model fit was determined.

\begin{tabular}{|l|c|c|c|}
\hline \multicolumn{1}{|c|}{ Fit indices } & Research Model & Recommended value & Source \\
\hline Chi-square & 616,$414 ; 275, \mathrm{p}<0,001$ & & \\
\hline$\chi^{2} /$ df & 2,242 & $<5$ & {$[51]$} \\
\hline GFI & 0,827 & $>0,8$ & {$[52]$} \\
\hline AGFI & 0,780 & $>0,8$ & {$[52]$} \\
\hline IFI & 0,925 & $>0,9$ & {$[51]$} \\
\hline TLI & 0,910 & $>0,9$ & {$[53]$} \\
\hline NFI & $0,872^{*}$ & $>0,9$ & {$[51]$} \\
\hline CFI & 0,924 & $>0,9$ & {$[54]$} \\
\hline RMSEA & 0,076 & 0,03 to 0,08 & {$[55]$} \\
\hline
\end{tabular}

* Value of $0.8<\mathrm{NFI}<0.9$ is considered acceptable [56], [57]

Table 3. Model fit indices 


\subsection{Research propositions testing}

In the research propositions check, the analysis focused on presenting standard regression weights related to the strength of the influence of independents on the dependent variables (path coefficient) and the determination of the critical ratio with his significant level. The critical ratio cut-off value is $>1.96$, while value $p<0.05$ represents a significant level. Table 4 shows the results of research propositions testing. Perceived ease of use MMC is significantly related to perceived usefulness of MMC $(\beta=0.609, C R=8,130, p<0.001)$. Perceived ease of use is significantly positive related to attitude toward $\mathrm{MMC}(\beta=0.185, \mathrm{CR}=2,393, \mathrm{p}<0,05)$. Perceived usefulness of MMC is significantly related to attitude toward $\mathrm{MMC}(\beta=0.523, \mathrm{CR}=$ $5,206, \mathrm{p}<0.001)$. Compatibility is significantly related to attitude towards MMC $(\beta=$ $0.376, \mathrm{CR}=4,998 \mathrm{p}<0.001)$. Internet privacy concern is not significantly negatively related to attitude towards $\mathrm{MMC}(\beta=-0,004, \mathrm{CR}=-0,082, \mathrm{p}>0,05)$. Attitude towards mobile advertising is significantly related to attitude towards $\mathrm{MMC}(\beta=0,301, \mathrm{CR}=$ $3,845, \mathrm{p}<0.001)$. Attitude towards $\mathrm{MMC}$ is significantly related to behavioural intention regarding use of $\mathrm{MMC}(\beta=0,864, \mathrm{CR}=8,452, \mathrm{p}<0.001)$. Additionally, the result of the path analysis is shown in Figure 2. The figure shows a low value for the path coefficient IPC $\rightarrow \mathrm{A}(0.00)$, which caused rejected the research proposition $\left(\mathrm{RP}_{5}\right)$, "Internet privacy concern has a negative influence on attitude towards $M M C$."

\begin{tabular}{|l|c|c|c|c|c|c|}
\hline $\begin{array}{l}\text { Research } \\
\text { proposition }\end{array}$ & $\begin{array}{c}\text { Independent } \\
\text { variable }\end{array}$ & $\begin{array}{c}\text { Dependent } \\
\text { variable }\end{array}$ & $\mathbf{B}$ value & CR & $\begin{array}{c}\text { P- } \\
\text { value }\end{array}$ & \\
\hline RP1 (+) & PEOU & PU & 0,609 & 8,130 & $* * *$ & Accept \\
\hline RP2 (+) & PEOU & A & 0,185 & 2,393 & 0,017 & Accept \\
\hline RP3 (+) & PU & A & 0,523 & 5,206 & $* * *$ & Accept \\
\hline RP4 (+) & CO & A & 0,376 & 4,998 & $* * *$ & Accept \\
\hline RP5 (-) & IPC & A & $-0,004$ & $-0,082$ & 0,935 & Reject \\
\hline RP6 (+) & ATMA & A & 0,301 & 3,845 & $* * *$ & Accept \\
\hline RP7 (+) & A & BI & 0,864 & 8,452 & $* * *$ & Accept \\
\hline
\end{tabular}

*** $\mathrm{P}<0,001, \mathrm{PU}$ - Perceived usefulness, PEOU- Perceived ease of use, CO- Compatibility, IPC- Internet privacy concern, ATMA-Attitude towards mobile advertisement, A-Attitude towards messenger chatbots, BI- Behavioral intention, CR-Critical ratio, $\beta$ - Standardised coefficient

Table 4. Regression weights structural equation model

Squared multiple correlation coefficient $\left(\mathrm{R}^{2}\right)$, indicates the percentage of the variance in the dependent variable that the independent variables explain collectively" [58]. The coefficient is used in practice to measure the goodness-of-fit of the models. The coefficient from Table 5 shows that $37,1 \%$ of the variance of the dependent variable „perceived usefulness" was explained by the independent variable "perceived ease of use." 


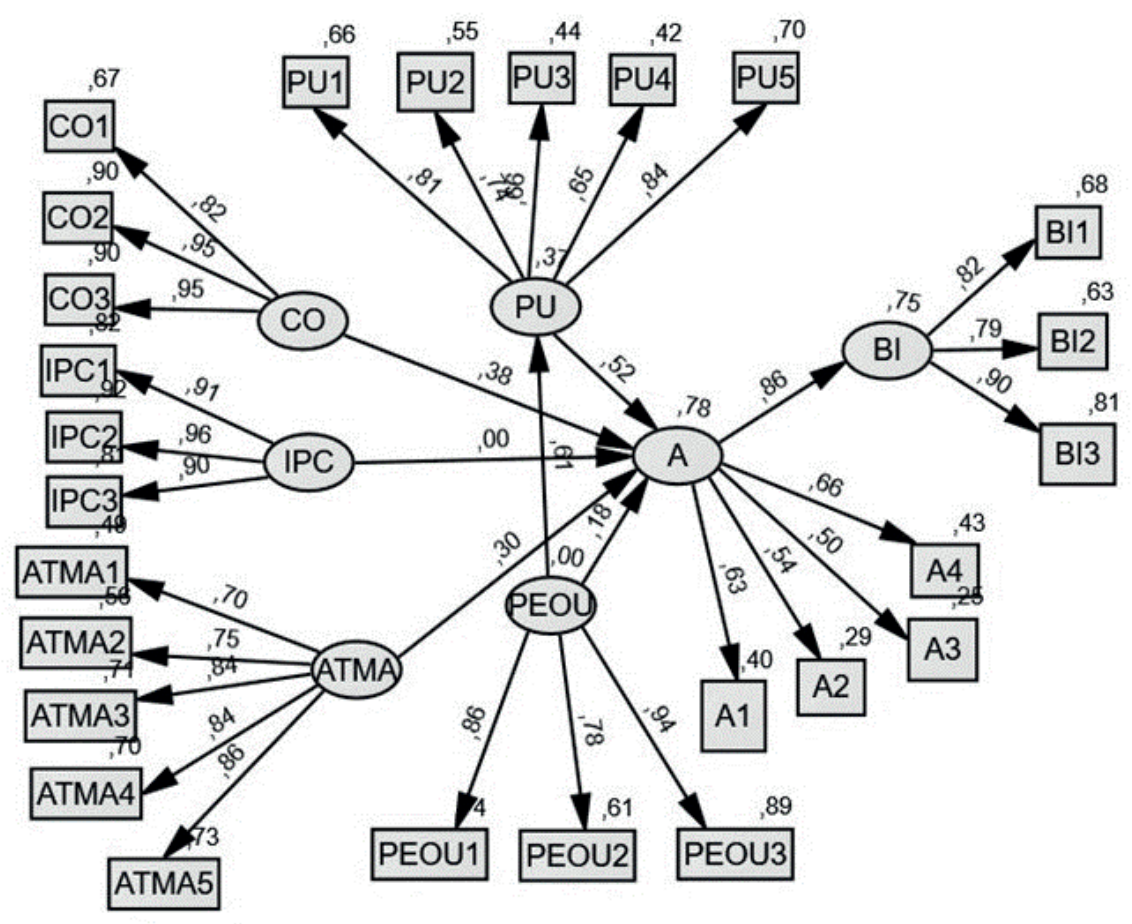

Figure 2. Path diagram

Furthermore, $78,3 \%$ of the variance of the second dependent variable, "attitude towards MMC," was explained by independent variables from the tested model (PEOU, PZ, CO, IPC, and ATMA). Finally, $74,6 \%$ of the variance dependent variable "Behavioural intension" was explained by independent variable (A). The obtained values indicate a good fit for the model.

\begin{tabular}{lc}
\hline Dependent Variables & $\begin{array}{c}\text { Percentage of variance explained } \\
(\mathbf{R}-\text { squared) }\end{array}$ \\
\hline \hline Perceived usefulness & 37,1 \\
Attitude towards MMC & 78,3 \\
Behavioural intension & 74,6 \\
\hline
\end{tabular}

Table 5. Squared multiple correlation coefficient $\left(\mathrm{R}^{2}\right)$

\section{Discussion and implications}

\subsection{Comparison with previous research}

The increasing use of artificial intelligence leads to the appearance of new innovative solutions in marketing communication. Chatbots represent a good example of using AI in building, maintaining, and developing customer relationships. The creation and 
use of chatbots within mobile applications is a recent innovation, and there is still a lack of relevant knowledge about their acceptance by mobile device users. With an intention to explore this area, research was conducted in the Republic of Croatia using the well-known TAM model and Theory of Diffusion of Innovations (DIT). The literature analysis shows that there is a lack of research on the topic of MMC acceptance by mobile device users, which is understandable given that this is a relatively new technological solution. For this reason, the other studies related to the acceptance of different technological solutions (mobile applications) related to using smartphones will also be examined.

The research's conceptual framework is based on the basic TAM model [14], which determines the intention to use through the user's attitude towards MMC based on the perception of their ease of use and their usefulness. Empirical research has found that perceived ease of use of MMC positively affects the perception of their usefulness $\left(\mathrm{RP}_{1}\right)$. Two recent papers [8] [44] on the subject have not considered this relationship, while papers related to the acceptance of m-commerce [16], m-payments [17], using mobile apps [18], and m-library [59] confirm the impact of ease of use perception on usefulness perception. The same studies determine the positive effect of these factors on the attitude about new technology (innovation) in accordance with the result of this research in testing research propositions $\mathrm{RP}_{2}$ and $\mathrm{RP}_{3}$. Kasilingham, in its research about attitudes towards MMC in mobile shopping, finds the same positive effect with a significance of 0.05 [8]. The mean score in this research for PU ranges from 3.3 to 4.0 and for PEOU from 4.1 to 4.4 . The higher percentage of agreement with the claims regarding the chatbot's usefulness can be explained through the rapid development of technology and the great connection between the mobile device and its owner who wants to be connected and make purchases regardless of their physical location and time. The high percentage of agreement with the proposed claims regarding the POEU might be directly related to the age of the respondents (15 to $27-99.5 \%$ ) who, as a rule, do not separate from their smartphones and very easily adopt all technological innovations. As the results show, a high degree of influence of PU $(B=0.523)$ on the attitude about MMC is evident.

Compatibility indicates how compatible some technology or innovation is with the activities, attitudes, thoughts, or lifestyle of an individual or future user. In this regard, compatibility was expected to positively affect millennials' attitude about $\mathrm{MMC}$, which the research confirmed. Research proposition $\mathrm{RP}_{4}$ is accepted. The result is conducted with multiple papers that also determines a strong relationship between credibility and the intention to embrace innovation related to smartphone using [60] [61] [62]. The mean score for compatibility ranges from 3.04 to 3.52 ; respondents' neutrality can be explained by the relative unknowing or lack of experience in using $\mathrm{MMC}$ that are just beginning to be used more significantly.

The negative influence of internet privacy concern on the attitude toward MMC has not been determined, and research proposition $\mathrm{RP}_{5}$ was rejected. The result is inconsistent with researches conducted by Kasilingam [8] and Sony \& Tyagi [44] regarding the acceptance of MMC. Kasilingam additional observes the influence of mediator variables gender, age, and experience and finds no negative effect of IPC on attitude when age is included. The author finds that perceived risk among older users 
$(>35)$ does not have a negative impact on the intention to use a chatbots for shopping. The author deals with the term risk, which, in a broader sense, includes and concerns about privacy. In this context, several studies point to the negative impact of risk on the adoption of new technologies [60] [62]. Respondents are neutral in terms of concerns about data privacy regarding using MMC (mean range up 3.01 to 3.21). The reason for less privacy concern can be found in the fact that using different mobile applications that make life easier and more enjoyable asks for some compensation in the form of sharing of certain personal data. So, despite some concerns, mobile app users agree to share the data with some benefit. Such behavior is presented as the socalled "privacy paradox" [63] [64] [65]. Lee et al. [66] emphasize that such irrational behavior stems from the expected benefit of sharing. According to Multiple research [67], the benefits of communicating with chatbots are 24-hour availability, instant answers, consistent answers, recorded answers, instant transactions, and personalization. Futthermore, research proposition $\mathrm{RP}_{6}$ was accepted, a positive effect of attitude toward mobile advertising on attitude toward MMC was established. Respondents are generally neutral (mean range up 2.50 to 3.65) regarding their attitude towards mobile advertising. However, they believe that mobile advertising is useful and important for promoting new products.

Research proposition $\mathrm{RP}_{7}$ was also accepted. A strong positive effect $(\beta=0.864)$ of attitudes about mobile messenger chatbots on behavioural intention was established. Respondents find mobile messenger chatbots interesting and fun and express the intention of their further use and recommendations (mean range up 3.55 to 4.07). The result is consistent with previous research about adoption and intention to using MMC [8] [44].

\subsection{Contribution to theory}

This research is based on testing a very well-known and exploited TAM model extended by a single predictor from Innovation Diffusion Theory and two predictors from recent research. The research results provide very useful information to scientists and professionals regarding the acceptance of $\mathrm{MMC}$ as an innovation in consumer communication based on artificial intelligence. With empirical research, all research propositions were accepted except one (RP5), thus supporting the proposed model to a large extent. The influence of PU, PEOU, CO, and ATMA on the attitude towards MMC was confirmed. All variables together explain the high $78.3 \%$ of the variance in $\mathrm{A}$.

PU has the greatest impact on the attitude towards MMC, which indicates that their practical usefulness significantly contributes to forming a positive attitude. A strong $\mathrm{CO}$ to A effect was also found, making respondents feel that $\mathrm{MMC}$ is compatible with their lifestyles. The impact of ATMA on A is somewhat smaller but strong enough to indicate how the attitudes about mobile advertising affect the attitude towards MMC. As MMC is also used in promotion, determining that relationship is very useful. 
The model also tested the impact of concern (fear) of misuse of data exchanged in communication with the machine (MMC). No significant negative impact of IPC on A was found. Research to date shows that generation $\mathrm{Z}$ and generation Millennials generally show some concern about the misuse of private data they share over the internet, but they believe that companies will not misuse that data for the purpose of harming them. The use of various mobile applications is conditioned by providing certain information or consent to use by accepting the installation of so-called cookies. Such everyday communication with companies and the desire to use certain (new) applications or content certainly has the effect of reducing concerns.

Finally, a significant positive effect of the attitude towards MMC on the intention to use MMC has been determined. Attitude towards MMC explain the high $74.6 \%$ of variance in BI. The result indicates the presence of a high level of intention to accept and use MMC as a communication and sales tool.

\subsection{Research implications}

In addition to new knowledge, the research results can be used by marketing and sales professionals in the application and design of a new communication and sales channel. It was found that the attitude about MMC is an important predictor of the use of MMC, and it is significantly influenced by the perception of ease of use and the perception of usefulness. It means that when applying MMC, the focus should be on values that will contribute to satisfaction and the perception of utility. Primarily their availability $24 / 7$, non-stop customer services, providing accurate information, ease of use, saving time for contacting retailers and the purchase itself, giving quick responses, using the nearest store locators, personalized communication, customized offer, customer engagement, and others. Millennials are a generation that has grown with the development of the internet and new technologies, and they cannot imagine their daily lives without using the benefits that these technologies provide. The adoption of MMC also depends on how much they support consumers' current patterns of behaviour (lifestyle) in online communication and shopping. Big data enables collecting and analyzing large amounts of data that reveal patterns of customer behaviour in communication and shopping. These findings are the basis for creating values that will support and build on existing consumer behavior patterns.

Furthermore, the results of the research support the privacy paradox phenomenon, which requires further development of the values offered by mobile messenger chatbots and their harmonization with user expectations. Research shows that millennials' attitude about mobile advertising is neutral (average mean 3.1 on a scale of 1-5). Several different studies about the attitude toward mobile advertising find that millennials perceive mobile ads as irritating and that they want ads to be fun, credible, and informative [68] [69]. Applying Big data makes it possible to provide them with the ads they want and reduce their unwontedness. Some previous studies particularly emphasize mobile ads' personalizations as the most important factor in their effectiveness [70]. 


\section{Conclusion}

By applying the TAM model, this paper aimed to predict the acceptance and use of MMC by consumers. The empirical research was conducted on a sample of 214 respondents who belong to the generation of Millennials according to their age. The obtained results confirm the research propositions; the younger population perceives $\mathrm{MMC}$ as a useful innovation that will facilitate and speed up their communication with companies and the brand as well as help them make purchases. As such, they are ready to accept and use it in the future. A positive attitude towards MMC has been established, which is significantly influenced by the compatibility of MMC with the previous habits and patterns of behaviour of that generation in the online ecosystem. Given the significant role of MMC as a promotional tool, impact of the attitude towards mobile advertising on attitude towards MMC also explored. The results confirm that this positive relationship exists. Furthermore, it was found that privacy concern is not a factor influencing attitude about MMC and the intention to use them.

A review of previous research found only two studies on the topic of this paper. Both studies confirm that millennials have a positive attitude towards MMC and intend to use them [8] [44]. The authors of these papers identify the negative impact of privacy concern (IPC) on the attitude towards MMC that this paper does not establish. By involving age mediators, Kasilingam finds that there is also no negative impact of IPC on attitude towards MMC. [8] The daily use of mobile applications and internet contents is conditioned by exchanging data, so less concern and greater trust in companies could be predicted.

A chatbot is a child of artificial intelligence that is constantly evolving and getting smarter, thus becoming a very effective tool in personalized communication. As such, they are slowly replacing existing direct marketing channels such as e-mail or e-mail marketing. For this reason, this research can be useful in preparing and conducting direct marketing campaigns and more broadly, in achieving and maintaining a competitive advantage in the market.

This research also has certain limitations. In research, the original TAM model is often extended by certain variables in accordance with the specifics of the considered technologies. This research focused on only three external factors influencing the acceptance of innovation. Although they, together with PU and PEOU, explain $78.3 \%$ of the variance of the attitude towards MMC by introducing other influencing factors (for example, perceived enjoyment, trust, price consciousness), the percentage of explanation of variance might be higher. Respondents in the study belong to the millennial generation that is technologically much more educated and experienced than the older population, so the results cannot be generalized. Accordingly, recommendations for further research go in the direction of including an older population who find it more difficult to adopt new technologies and prefer to talk to a live salesperson and a company representative. As MMC and the application of artificial intelligence are in the early stages of implementation, there will be new impacts on their use that need to be recognized and explored over time. 


\section{References}

[1] C. Krum, Mobile Marketing, London: Pearson, 2010, p. 1.

[2] B. Marr, Big Data, Using smart big data. Analytics and metrics to make better decision and improve performance, Hoboken: John Wiley \& Sons,, 2015, p. 10.

[3] S. Tong, X. Luo and B. Xu, "Personalized mobile marketing strategies," Journal of the Academy of Marketing Science, vol. 48, no. 1, pp. 64-78, 2019.

[4] D. Chaffey and F. Ellis-Chadwich, Digital Marketing, Strategy, Implementation and Practice, London: Pearson, 2019, p. 251.

[5] Y. Wang and S. Petrina, "Using Learning Analytics to Understand the Design of an Intelligent Language Tutor," International Journal of Advanced Computer Science \& Applications, vol. 4, no. 11, pp. 124-131, 2013.

[6] "Chatbot's: The Definitive Guide (2021)," [Online]. Available: https://www.artificial-solutions.com/chatbots\#1. [Accessed 12 March 2021].

[7] D. L. Kasilingam, "Understanding the attitude and intention to use smartphone chatbots for shopping," Technology in Society, pp. 101-280, 2020 .

[8] J. Zeng, "Chatbots and Customer Experience in 2020," 20 November 2020. [Online]. Available: https://www.ama.org/marketing-news/chatbots-andcustomer-experience-in-2020.

[9] Statista, "Number of mobile messaging users worldwide," 21 November 2020. [Online]. Available:

https://www.statista.com/statistics/483255/number-of-mobile-messagingusers-worldwide/.

[10] Statista, "Most popular global mobile messenger apps," November 2020. [Online]. Available: https://www.statista.com/statistics/258749/mostpopular-global-mobile-messenger-apps/.

[11] E. M. Rogers, Diffusion of innovations, fifth edition, New York: The free Press, 2003.

[12] R. P. J. Agarwal, "A conceptual and operational definition of personal innovativeness in the domain of information technology"," Information Systems Research, vol. 9, no. 2, pp. 204-215, 1998.

[13] F. D. Davis, "Perceived usefulness, perceived ease of use, and user acceptance of information technology," Engineering, Psychology, Computer Science, vol. 13, no. 3, pp. 319-340, 1989. 
[14] O. Al-Hurjan, E. Al-Lozi and M. Al-Debei, "Examining eDemocracy Adoption Intention for Digital Society: An Integrative Model," in Eighth International Conference on Digital Society Barcelona, Barcelona, Spain, 2014.

[15] Y.-Y. Shih and C.-Y. Chen, "The study of behavioral intention for mobile commerce: via integrated model of TAM and TTF.," Quality \& Quantity,, vol. 47, no. 02, p. 1009-1020, 2011.

[16] A. Bailey, I. Petina, S. Mishra and B. Mimoun, "Mobile payments adoption by US consumers: an extended TAM," International Journal of Retail \& Distribution Management, vol. 45, no. 6, pp. 1-17, 2017.

[17] R. Subhadin, "App adoption and switchhing behavior: applying the extended TAM in smartphone aff usage," Journal of information System and Technology Management, vol. 14, no. 2, pp. 239-261, 2017.

[18] E. Mao, M. Srite, J. Thatcher and O. Yaprak, "A research model for mobile phone use and customer shopping behavior: Evidence in the US Turkey," Journal of Global Information Technology Management, vol. 8, no. 4, pp. 7-28, 2005.

[19] N. T., S. Balasubramanian and D. Kasilingam, "The moderating role of device type and age of users on the intention to use mobile shopping applications," Technol. Soc., vol. 53, pp. 79-90, 2018.

[20] A. Al-Hujran, I. Aloudat and I. Altarawneh, "Factors Influencing Citizen Adoption of E-Government in Developing Countries," International Journal of Technology and Human Interaction, vol. 9, no. 2, pp. 1-19, 2013.

[21] L. Yang, Y. Bian, X. Zhao, X. Liu and X. Yao, "Drivers' acceptance of mobile navigation applications," International Journal of Human-Computer Studies, vol. 145, 2021.

[22] N. Ugur and A. Turan, "Mobile Applications Acceptance: A Theoretical Model Proposal and Empirical Test," International Journal of E-Adoption, vol. 11, no. 2, pp. 13-21.

[23] R. Chinomona, "The influance of perceived ease of use and perceived usefulness on trust and intention to use mobile social software," African Journal for Physical Health Education, Recreation and Dance, pp. 15-25.

[24] B. Mak, P. Beckman and N. Bohn, "Perceived Usefulness and Satisfaction of Mobile Phone for Users with Disabilities," International Journal of Innovation and Technology Management, vol. 13, no. 2, pp. 10-36.

[25] M. Eeuwen, "Mobile conversational commerce: messenger chatbots as the next interface between business and consumers," 2017. [Online].

Available: 
https://essay.utwente.n1/71706/1/van\%20Eeuwen_MA_BMS.pdf. [Accessed March 2021].

[26] G. C. Moore and I. Benbasat, "Development of an instrument to measure the perceptions of adopting an information technology innovation," Information System Research, vol. 2, no. 3, pp. 192-222, 1995.

[27] L. Chen, M. Gillenson and D. L. Sherrell, "Enticing Online Consumers: An Extended Technology Acceptance Perspective," Information \& Management, vol. 9, no. 8, pp. 705-719, 2002.

[28] L. R. Vijayasarathy, "Predicting consumer intentions to use online shopping: the case for an augmented technology acceptance model," Information and Management, pp. 747-762, 2004.

[29] K. Kanchanatanee, N. Suwanno and A. Jarernvongrayab, "Effects of Attitude toward Using, Perceived Usefulness," Journal of Management Research, vol. 6, no. 3, pp. 24-35, 2014.

[30] J. O'Donnell, M. Jackson, M. Shelly and J. Ligert, "Australian Case Studies in Mobile Commerce," Journal of Theoretical and Applied Electronic Commerce, vol. 2, no. 2, pp. 1-18, 2007.

[31] C. W. Reports, "Leap of Faith: Using the Internet Despite the Dangers, Consumer Affairs Webwatch," 01 December 2020. [Online]. Available: http://www.consumerwebwatch.org/pdfs/princeton.pdf.

[32] R. Zhang, J. Q. Chen and C. J. Lee, "Mobile Commerce and Consumer Privacy Concerns," Journal of Computer Information Systems, vol. 53, no. 4, pp. 31-38, 2016.

[33] J. Khana, H. Abbasa and J. Al-Muhtadia, "Survey on Mobile User's Data Privacy Threats and Defense Mechanisms," Procedia Computer Science, vol. 56, pp. 376-383, 2015.

[34] C. S. Gates, J. Chen, N. Li and R. W. Proctor, "Effective risk communication for Android apps," IEEE Transactions on Dependable and Secure Computing,, vol. 11, no. 3, pp. 252-265, 2014.

[35] L. Qin and H. Yan, "Attitude towards Mobile Advertising and Mobile Web Information Acquisition Behaviour: Perspectives from the Advertising Value, Credibility and Self-efficacy," Education and Humanities Research, vol. 72, pp. 368-373, 2017.

[36] S. Rajesh, G. Raj, S. Dhuvandranand and D. R. Kiran, "Factor influencing customer's attitude towards SNS advertisement: Evidence from Mauritius," Studies in Business and Ecomomics,, vol. 14, no. 2, pp. 141-159, 2019..

[37] M. M. Tsang, S. C. Ho and T. P. Liang, "Consumer attitudes toward mobile advertising: An empirical study," International Journal of Electronic Commerce, vol. 8, no. 3, pp. 65-78, 2004. 
[38] P. W. Farris, N. T. Bendle, D. J. Reibstein and P. E. Pfeifer, Marketing Metrics, The Definitive Guide to Measure Marketing Perfomance, Second ed., New Jersey: Wharton School Publishing, 2010, p. 53.

[39] N. Aziz and A. M. Ariffin, "Ariffin Exploring Consumers Attitude towards Web Advertising and its Influence on Web Ad Usage in Malaysia," Jurnal Pengurusan, vol. 31, pp. 55-63, 2010.

[40] V. Slunjski, D. Dobrinić and I. Gregurec, "Croatian customers attitude towards mobile advertising-SEM aproach," in 63th International Scientific Conference on Economic and Social Development, Zagreb, 2020.

[41] S. Unal, A. Ercis and E. Keser, "Attitudes towards Mobile Advertising - A Research to Detrmine the Differences between the Attitude of Youth and Adults," Procedia Social and Behavioral Sciences, vol. 24, pp. 361-377, 2011.

[42] S. Liao, J. C. Hong, M. H. Wen, Y. C. Pan and . Y. W. Wu, "Applying Technology Acceptance Model (TAM) to explore Users' Behavioral Intention to Adopt a Performance Assessment System for E-book Production," EURASIA Journal of Mathematics, Science and Technology Education, vol. 14, no. 10, 2018.

[43] R. Sony and V. Tyagi, "Acceotance of Chat bots by Millennials Consumers," International Journal for Research in Engineering Application \& Management, vol. 04, no. 10, pp. 429-432, 2019.

[44] J. Kim and Y. \& Han, "Why smartphone advertising attracts customers: A model of web advertising, flow, and personalization," Computers in Human Behavio, vol. 33, pp. 256-269, 2014.

[45] E. Murillo, M. Merino and A. Núñez, "The advertising value of Twitter Ads: a study among Mexican Millennials," Revista Brasileira de Gestao de Negocio, vol. 18, no. 61, pp. 436-456, 2016.

[46] D. Dobrinić, I. Gregurec and D. Dobrinić, "The Advertising Attitudes of Internet Ads: A Study Among Croatian Generation Z," in Book of Proceedings, 61st International Scientific Conference on Economic and Social Development, Varaždin, 2020.

[47] S. Ahmed, N. Zulkurnain and F. Khairushalimi, "Assesing the Validity and Realibility of a Measurement Model in Structural Equation Modeling (SEM)," British Journal of Mathematics and Computer Science, vol. 15, no. 3, pp. 1-8, 2016.

[48] T. Hernaus, B. V. Vuksić and P. R. Bach, "Influence of strategic approach to BPM on financial and non-financial performanse," Baltic Journal of Management, vol. 7, no. 4, pp. 376-396, 2012.

[49] A. Field, Discovering statistics using IBM SPSS Statistics, Thousand Oaks: SAGE Publications Ltd, 2013. 
[50] E. Park and K. J. Kim, "An Integrated Adoption Model of Mobile Cloud Services: Exploration of Key Determinants and Extension of Technology Acceptance Model," Telematics and Informatics, vol. 31, no. 3, pp. 376385, 2014.

[51] A. Halmi, Multivarijantna analiza, Zagreb: Alinea, 2016, p. 175.

[52] H. Han, W. Kim and S. S. Hyun, "Overseas travelers' decision formation for airport-shopping behavior," Journal of Travel \& Tourism Marketing,, vol. 31, no. 8, pp. 985-1003, 2014.

[53] L. T. Hu and P. M. Bentler, "Cutoff criteria for fit indexes in covariance structure analysis: Conventional criteria versus new alternatives," Structural equation modeling: a multidisciplinary journal,, vol. 5, no. 1, pp. $1-55,1999$.

[54] J. F. Hair Jr, M. Sarstedt, L. Hopkins and V. G. Kuppelwieser, "Partial least squares structural equation modeling (PLS-SEM)," European business review., vol. 2, pp. 106-121, 2014.

[55] C. Forza and R. Fillppini, "TQM impact on quality conformance and customer satisfaction: a causal model," International journal of production economics, vol. 55, no. 1, pp. 1-20, 1998.

[56] P. J. Greenspoon and D. H. Saklofske, "Confirmatory factor analysis of the multidimensional students life satisfaction scale," Personality and Differences, vol. 25, no. 5, pp. 965-971, 1998.

[57] J. Frost, "How To Interpret R-squared in Regresion Analysis,," [Online]. Available: https://statisticsbyjim.com/regression/interpret-r-squaredregression. [Accessed 1202 2021].

[58] H. Rafique, A. Shamim and F. Anwar, "Investigating acceptance of mobile library application with extended technology acceptance model (TAM)," Computers \& Education, vol. 145, 2019.

[59] A. Gumussoy, A. Kaya and E. Ozlu, "Determinants of Mobile Banking Use: An Extended TAM with Perceived Risk, Mobility Access, Compatibility, Perceived Self-efficacy and Subjective Norms," in Industrial Engineering in the Industry 4,0 Era, F. A. C. Calisir, Ed., Springer, 2018, pp. 225-238.

[60] B. Moti and N. Walia, "The Effect of Compatibility, Social Influence, and Perceived Ease of Use on Perceived Usefulness of Mobile Payment Services," International Journal of Scientific \& Technology Research, vol. 9, no. 2, pp. 1865-1873, 2020.

[61] A. Raza, A. Umer and N. Shah, "New determinants of ease of use and perceived usefulness for mobile banking adoption," International Jurnal Electronic Customer Relationship Management, vol. 11, no. 1, pp. 44-65, 2017. 
[62] P. A. Norberg and D. A. Horne, "The privacy paradox: Personal information disclosure intentions versus behaviors," Journal of Consumer Affairs, vol. 41, no. 1, pp. 100-126, 2007.

[63] B. Brown, "Studying the internet experience. HP Laboratories Technical Report (HPL2001-49)," 26 November 2020. [Online]. Available: http://www.hpl.hp.com/techreports/2001/HPL-2001-49.pdf (accessed 26 November, 2020).

[64] M. C. Oetzel and T. Gonja, "The online privacy paradox: a social representations perspective," in An International Conference on Human Factors in Computing Systems, Vancouver, Canada, 2011.

[65] H. Lee, H. Park and J. Kim, "Why do people share their context information on Social Network Services? A qualitative study and an experimental study on users' behavior of balancing perceived benefit and risk,"," International Journal of Human Computer Studies, vol. 71, no. 9, pp. 862-877, 2013.

[66] A. Multiple, "Top 12 Benefits of chatbots in 2020. The Ultimate Guide.," 20 November 2020. [Online]. Available:

https://research.aimultiple.com/chatbot-benefits/.

[67] E. Liu, R. Sinkovics, N. Pezderka and P. Haghirian, "Determinants of Consumer Perception toward Mobile Advertising - A Comparison between Japan and Austria," Journal of interactive marketing, vol. 26, no. 1, pp. 21$32,2012$.

[68] M. Aramendia-Muneta and C. Olarte-Pascual, "Consumer attitudes towards mobile advertising: an updated vision," International Journal of Internet Marketing and Advertising, vol. 13, no. 3, pp. 235-252, 2019.

[69] P.-T. Chen and H.-P. Hsieh, "Personalized mobile advertising: Its key attributes, trends, and social impact," Technological Forecasting and Social Change, vol. 79, no. 3, p. 543-557, 2012.

[70] R. Ren, J. W. Castro, S. T. Acuna and J. de Lara, "Usability of Chatbots: A Systematic Maping Study," International Journal of Software Engineering and Knowledge Engineering, vol. 29, pp. 1673-1702 